\title{
Porokeratotic Eccrine Ostial and Dermal Duct Nevus
}

National Cancer Institute

\section{Source}

National Cancer Institute. Porokeratotic Eccrine Ostial and Dermal Duct Nevus. NCI

Thesaurus. Code C4740.

A rare, congenital disorder of the eccrine sweat ducts that presents as grouped keratotic papules and plaques with a linear distribution and/or multiple punctate pits filled with tiny keratotic plugs resembling comedones. The lesion are usually located on the acral portion of a limb. 